\title{
A intuição categorial, o problema das categorias e a
} doação do ser

\author{
The categorial intuition, the problem of categories and the \\ donation of Being \\ MARCos AuRÉLIO FERNANDES ${ }^{a}$
}

\section{Resumo}

Este texto pretende expor o significado da descoberta fenomenológica da intuição categorial, feita por Husserl, para o tradicional problema das categorias e para o novo encaminhamento da questão do ser, que se deu com a investigação e meditação de Heidegger. Expõe o contexto em que a descoberta foi realizada: o do esclarecimento do conhecimento em referência ao modo de captação do ente em seu ser, a partir da sensibilidade e do entendimento. Indica como o método fenomenológico transcendental, através da tematização da intencionalidade, com sua análise noéticonoemática, possibilitou uma retomada do problema das categorias numa nova luz. Seguindo pela via da analogia, aponta-se que o categorial se dá propriamente numa intuição, assim como o sensível, embora de modo diverso. A descoberta da intuição categorial indica que o categorial é mais do que forma. É uma verdadeira e própria datidade. Nela e com ela acontece uma genuína doação do ser. Tradicionalmente, o lógos apophantikós serviu de fio condutor para o tratamento do problema das categorias, as determinações universais do ser. Assim, os modos de ser são estabelecidos a partir dos modos do falar e dizer. Também em Kant é com base na estruturação dos juízos que Kant deduz as categorias. Mas com a descoberta da datidade da intuição categorial a doação do ser se liberta do juízo. Com isso, o contexto da descoberta, a da elucidação fenomenológica do conhecimento, e a via de sua realização, a da analogia, podem ser superados, em favor da abertura do arquifenômeno do ser.

Palavras-chave: Intuição categorial. Categoria. Ser. Fenomenologia.

a Universidade de Brasília (UnB), Brasília, DF, Brasil. Doutor em Filosofia, e-mail: maffernandes69@gmail.com 


\section{Abstract}

This text intends to expose the significance of Husserl's phenomenological discovery of categorial intuition to the traditional problem of categories and to the forwarding of the question of being that occurred with Heidegger's research and meditation. It expounds the context in which this discovery was made: that of the enlightenment of knowledge about to the mode of apprehension of the being as such (in its entity), from the sensibility and the understanding. It indicates how the transcendental phenomenological method, through the thematization of intentionality, with its noetic-noematic analysis, enabled a resumption of the problem of categories in a new light. Following the path of analogy, it is pointed out that the categorial occurs properly in and as intuition, as well as the sensible, although in a different way. The discovery of categorial intuition indicates that categorial is more than form. It is a true and proper donation. In her and with it happens a genuine donation of being. Traditionally, the apophantikós logos served as the conducting wire for the treatme $n t$ of the problem of categories, the universal determinations of being. Thus, the modes of being are established from the ways of speaking and saying. Likewise, in Kant, it is based on the structuring of the judgments that Kant deduces the categories. But with the discovery of the donation of categorial intuition the donation of being is freed from judgment. Thus, the context the discovery of the categorial intuition, the phenomenological elucidation of knowledge, and the way of its realization, the analogy, can be overcome, in favor of opening the originating phenomenon of being.

Keywords: Categorial intuition. Category. Being. Phenomenology.

Pretende-se, aqui, expor o significado da descoberta fenomenológica da intuição categorial, feita por Husserl, para o tradicional problema das categorias e para o novo encaminhamento da questão do ser, que se deu com a investigação e meditação de Heidegger. O objetivo não é falar de Husserl ou de Heidegger, nem da pesquisa sobre ambos. O escopo é falar das coisas mesmas em questão que ambos, a partir de pontos de vista diversos, através de vias diversas, e tendendo a diversos horizontes da investigação fenomenológica, colocaram em discussão ao tratar da descoberta da intuição categorial. Pretende-se mostrar como o tradicional problema das categorias, que tem a sua arrancada no pensamento grego, especialmente em Aristóteles, e que sofre uma interpretação moderna em Kant, recebe uma nova luz.

\section{O contexto da descoberta da intuição categorial}

No sexto capítulo da sexta das Investigações lógicas, Hussel traz à fala uma descoberta fundamental da fenomenologia: a intuição categorial (HUSSERL, 1993, 
p. 128-221). Para Heidegger, cujo pensamento desde a leitura da dissertação de Brentano Da múltipla significação do ente segundo Aristóteles esteve se movendo na direção da questão do sentido do ser, esta descoberta significou o surgimento de uma nova orientação do âmbito da questão como um todo (HEIDEGGER, 1986, p. 376-377). A sexta investigação, especialmente o sexto capítulo, foi, para Heidegger, o foco em que a questão do sentido do ser pôde se acender. A descoberta da intuição categorial não só lança nova luz sobre o problema metafísico das categorias, como também contribui para o movimento e o encaminhamento da questão do sentido do ser que, pelo simples fato de ser colocada, já ensaia uma superação da própria metafísica.

O sexto capítulo abre a segunda secção da sexta investigação. Esta secção se chama Sinnlichkeit und Verstand (sensibilidade e entendimento). O lugar e o contexto em que aparece a intuição categorial de modo decisivo nas Investigações Lógicas é algo digno de ser notado. Esta investigação lógica visa expor os elementos de uma elucidação fenomenológica do conhecimento. Não se trata de uma investigação a respeito do ente e do ser e, a partir daí, a respeito do conhecer e pensar, mas, segundo a tendência moderna, de uma investigação a respeito do conhecer e pensar e, a partir daí, a respeito do ente e do ser. Mais precisamente, o contexto da irrupção desta descoberta fenomenológica fundamental, da intuição categorial, é o da discussão do tema sensibilidade e entendimento. Verstand, entendimento, significa, aqui, a faculdade do conceito. É a unidade de sensibilidade e entendimento que possibilita a constituição do objeto (Gegenstand) enquanto objeto da experiência (Erfahrung). O contexto, portanto, é o da problemática da teoria da experiência, o que ata a discussão de Husserl à herança kantiana, isto é, do método transcendental.

A cisão da realidade em mundo sensível e mundo inteligível, a partir dos modos de captação do ente em seu ser, a saber, a partir da sensibilidade e do entendimento, constitui o fundo metafísico do pensamento ocidental. O método transcendental, de certo modo, está sob a envergadura desta decisão e cisão históricas da metafísica na tradição ocidental. Lembremo-nos, por exemplo, da dissertação que Kant escrevera, em 1870, para se tornar professor ordinário, intitulada De mundis sensibilis atque intelligibilis forma et principiis (Da forma e dos princípios do mundo sensível e do inteligível), divisor de águas entre o seu período pré-crítico e o seu período crítico. Esta distinção, por sua vez, remonta a Platão. Com este, o Todo (a uni- 
totalidade do real e das realizações) se cindiu em dois hemisférios: a realidade do ente sensível, o aisthetón, que pode ser captado com a aísthesis, a percepção sensorial; e a realidade do ente inteligível, o noetón, que pode ser captado através do noûs, ou seja, do intelecto ou da razão (no sentido de percepção intelectiva). Trata-se de uma diferença fundamental na tradição do pensamento ocidental, que rege toda a metafísica, isto é, todo o pensamento do ente no todo, na perspectiva do ser, que é tomado como fundamento, presença que leva o ente a presentar-se de modo apropriado fundamento, portanto, pro-dutor do ente, cujo fundar se doa de vários modos: como causação ôntica do real, como possibilitação transcendental da objetualidade dos objetos, etc. (HEIDEGGER, 1999, p. 95-96).

Kant põe em questão, no modo da chamada filosofia transcendental, o tema da essência do conhecimento. O método transcendental não é um mero instrumento de trabalho para construir um sistema. O método transcendental é a filosofia enquanto filosofia. É uma práxis do pensamento, uma tomada de posição epocal, em que reinam as equações: real $=$ objeto, realização $=$ objetivação e realidade $=$ objetividade. Nesta con-juntura histórica, o ente é tomado enquanto cognoscível, e o seu fundamento, o ser, como a cognoscibilidade (objetualidade no sentido da representabilidade), e o fundar do ente é tomado como possibilitação transcendental da objetualidade.

Em Husserl, a filosofia se torna fenomenologia transcendental. Ela visa fornecer o sistema gradualmente elaborado de todos os objetos possíveis da consciência, e, nisso, o sistema de suas categorias formais e materiais, seguindo os fios condutores dos modos em que se dão as constituições de sentido nas mais diversas regiões de ser. Cada região de ser, com sua constituição de ser própria, é uma estrutura de sentido à qual corresponde uma pluralidade de projetos de sentido, de compreensões de sentido. A fenomenologia, assim, se constitui como uma investigação das constituições de sentido das regiões de ser, em suas estruturas, construções, ordenações. Nenhum objeto é, no entanto, pensável e cognoscível sem seu sujeito, isto é, sem seu modo de subjetividade correspondente. A análise das constituições de sentido e da estrutura dos objetos (análise noemática) exige, assim, uma investigação das formas de subjetividade (análise noética). Ambos os polos são 
imbricados de tal modo a constituir uma unidade, uma única coisa em questão: a estrutura noético-noemático global da intencionalidade (ROMBACH, 1988, p. 120).

Intencionalidade, na fenomenologia transcendental, quer dizer o ser direcionado do sujeito ao objeto e o ser direcionado do objeto para o sujeito. Mas não se trata de qualquer direcionamento. Trata-se, antes, daquele direcionamento essencial, em que aparecem as formas fundamentais da subjetividade e as constituições fundamentais das objetualidades que lhe correspondem.

O fenômeno é, em Husserl, a fenomenologia do fenômeno que se dá como o recolhimento desta referência mútua fundamental, que é a intencionalidade. A intencionalidade é o entre do inter-esse em que sujeito e objeto podem se encontrar e ser um para o outro. É em virtude da transiência da intencionalidade que os objetos podem se tornar presentes e ser presentados, apresentados, representados. É também em virtude desta transiência que a consciência - enquanto consciência, justamente, intencional — pode gerar estruturações de sentido. A intencionalidade é, pois, o medium, a mediação fundamental, que possibilita a correlação sujeito-objeto. Ela é, na fenomenologia transcendental, o arquifenômeno.

\section{A via da analogia na exposição da intuição categorial}

O título do sexto capítulo da sexta das Investigações Lógicas é Sinnliche und Kategoriale Anschaunngen (intuições sensiveis e categoriais). Em jogo está, pois, o relacionamento de intuição sensível e intuição categorial. Este relacionamento tem o caráter de analogia. Já o título "intuição categorial”, em sua formulação mesma, se estrutura a partir de e com base em uma relação. Ponto de partida, o analogado principial, é a intuição sensível. Parte-se dela para se chegar à intuição categorial (HEIDEGGER, 1986, p. 374). Intuição sensível é o polo noemático da percepção sensorial (polo noético). Isto quer dizer: a percepção sensorial tem como correlato intencional o objeto sensível. O fundamento do sensível é a býle, a matéria sensível. $\mathrm{Na}$ filosofia transcendental, matéria é o que afeta a sensibilidade. Hiléticas são as datidades sensíveis, isto é, o que se doa nessa afecção: o azul do céu, o amarelo do ipê, o som de uma melodia, o sabor de um alimento, etc. Entretanto, o que é o percebido do perceber sensível? Evidentemente, não só as datidades sensíveis, pois, com elas, na percepção, torna-se visível, faz-se fenômeno, um objeto. A datidade do 
objeto, sua doação fenomenal, não se dá com a mera impressão sensível. Não se pode reduح̨ir, isto é, restringir e reconduzir, percep̧̧ão a sensação e sensação a impressão. O objeto percebido, enquanto tal, não é dado na impressão sensível. O objeto, enquanto objeto, melhor, a objetualidade do objeto, não pode ser percebida sensivelmente. Isto quer dizer: o fato de que o objeto é objeto, não provém de uma intuição sensível.

Ora, enquanto escrevo este arrazoado, tenho diante de mim este livro de capa amarela. Tomo em consideração agora este livro não enquanto livro, mas enquanto objeto sensível. O que é percebido na minha percepção não é meramente o amarelo de sua capa, a sua extensão espacial etc. O que é percebido é, justamente, o objeto como tal e como um todo, embora esta percepção comporte adumbramentos. $\mathrm{Na}$ percepção do objeto enquanto tal está em jogo mais do que a recepção de datidades sensíveis. A percepção é um fenômeno uno, simples, e, no entanto, possui uma estrutura rica, variada, múltipla, diversa (LEÃO, 2008, p. 51-61). Na intencionalidade da percepção há o perceber, o percebido e o caráter-de-ser-percebido, a perceptividade (HEIDEGGER, 1997, p. 64-67). Isso soa tautológico! De fato. Parece uma trivialidade óbvia. E é. Mas é na raiz da trivialidade, é no bojo do óbvio, que o pensamento se instala de modo questionador. A ciência e o senso comum seguem adiante. $\mathrm{O}$ pensamento vê no trivial, no óbvio, a coisa que provoca a pensar. Mas, o que é que dá a pensar esta simplicidade e, ao mesmo tempo, multifariedade da percepção?

Enquanto intencionalidade, a percepção é um direcionamento do sujeito, o percipiente, para um objeto, o percebido. Toda percepção é uma percepção de algo. Em toda percepção há uma intentio (intenção), isto é, um tender-para, um direcionarse a, um orientar-se por... e um intentum, aquilo para o que se tende, a que se direciona, pelo que se orienta. Ora, isso é, na verdade, próprio de toda consciência-de. O que seria o específico da percepção? Na percepção o percebido se dá a si mesmo por si mesmo "em carne e osso", “em pessoa”, em concreto, vivamente. Na percepção, o ente (o real, o objeto) é descoberto de modo imediato e primeiro. Nela se desvenda o ente como o presente em sua presença, ou, se quisermos, como o existente em sua existência. A doação do ser como existência, seu desvendamento, acontece de uma maneira pré-conceitual, isto é, prévia à conceituação. O caráter de anterioridade desta 
doação prévia, porém, não é temporal. É essencial, constitutiva. É condição de possibilidade do comportamento perceptivo enquanto tal. O desvendamento da existência possibilita a descoberta do existente.

Perceber o objeto enquanto tal significa apreendê-lo como uma coisa (Ding). O livro de capa amarela, que jaz sobre a minha mesa, é uma coisa. $\mathrm{Na}$ linguagem da tradição filosófica, este objeto, esta coisa, é uma substância (ens in se). O livro me dado como uma coisa que existe em si mesma, que oferece uma resistência e uma consistência de ser própria. Ele aparece e se doa de modo diverso de um acidente (ens in alio), o qual só tem o ser como determinação da substância. É o caso, pois, do amarelo da capa do livro. Este, o amarelo, com efeito, se dá como uma determinação acidental da substância. Acontece de o livro ser amarelo. Este ser é casual, fortuito, não necessário e nem universal.

Se digo "este livro é amarelo" este reclamo não somente põe em causa a coisa — o livro — em si mesma, mas também a coisa em sua coloração — amarela. Nós, assim, reclamamos a coisa em sua feição, mais precisamente, no seu "qualis" (serassim). Neste reclamo, a coisa - o livro — é qualificada como amarela. Torna-se manifesta, assim, uma poiótes, uma qualitas, um ser-assim, uma qualidade. Emerge, assim, o ser-em-uma-feição do livro. Isso que é qualificado — o livro — aparece, assim, como um bypokeimenon, um subiectum, isto é, como algo que está presente aí, de modo subjacente, e sobre o qual se fala, ao se dizer: "este livro é amarelo”. O livro se dá na forma de uma substância. A proposição expressa pelo enunciado é: “este livro é amarelo”. A proposição diz, isto é, mostra, deixa ver, ressaltando, o ser-amarelo deste livro. Substância, qualidade, assim como quantidade, relação, etc., são tomados, na tradição, como modos fundamentais do ser do ente, que são chamados em causa, mediante diferentes tipos de enunciados concernentes ao ente enquanto ente. Estes modos fundamentais do ser do ente que vêm a fala no discurso são as categorias. No discurso, o homem reclama o ser do ente num modo multifário. Mas isso só é possível uma vez que o ser do ente, tacitamente, em se dando fenomenalmente, reclama o olhar, isto é, a atenção e a consideração do pensar, e a correspondência do falar e do dizer do homem, no exercício do discurso. 


\section{Juízo, categorias e intuição categorial}

A forma fundamental pela qual o homem grego — na filosofia primeira aprendeu a pôr-se na proximidade do ser do ente era o lógos apophantikós, o falar e dizer que se põe em condição de deixar vir à luz e mostrar-se o ente, a partir dele mesmo. É o discurso que não somente fala sobre a coisa mesma, mas também a partir dela mesma, deixando-a mostrar-se em si mesma. Entre os gregos, o lógos apophantikós era, assim, o fio condutor para tornar manifesto os modos fundamentais do ser do ente. Aristóteles usou a expressão kategoriai tou óntos para dizer aqueles predicados mais abrangentes e originários que se podem atribuir ao ente enquanto ente.

No discurso filosófico, a partir de Aristóteles, as categorias são as determinações últimas do ser do ente. Nelas o pensar procura dispor um saber sobre o ser do ente, ou seja, procura deixar iluminar a verdade sobre o ente que se patenteia enquanto tal no todo (mundo). Neste sentido, as categorias são os conceitos filosóficos fundamentais. Pensar, refletir, meditar, a respeito das categorias é, pois, um modo de pôr-se na proximidade do ser e da sua verdade, isto é, de sua abertura e manifestação. A tradição chamou as categorias do ente de "gêneros supremos", por serem gêneros que não podem se tornar espécies de outros gêneros. Tratam-se de predicados universais, que se referem ao ente enquanto ente, isto é, ao ente no seu todo.

Aristóteles falou do orthós lógos — o discurso correto. Isso sofreu uma reinterpretação no horizonte da experiência romana da veritas. O homem romano entende a verdade num horizonte judicial, isto é, na perspectiva de uma quaestio (questão, o que está em causa, num litígio), de uma disputatio in utram que partem (disputa que vai na direção de uma e de outra parte em litígio). A veritas (verdade) é uma espécie de justiça (iustitia): é a aequitas (equidade) enquanto rectitudo (retidão) da recta ratio (da reta razão). O lógos se torna oratio (oração) e ratio (razão). O lógos apophantikós se torna iudicium (juízo). Daí, a preocupação com o estabelecimento de regras (regulae) e cânones (canon = prumo), que tornassem retos o raciocínio do orador. A lógica é a disciplina que estabelece estas regras. Ela se interessa em perguntar o que pertence a um enunciado, para que ele seja um enunciado e seja um enunciado justo, correto, verdadeiro. Ela se preocupa com a recta determinatio iustorum, com a reta 
determinação daquelas proposições que são justas, pelo iudicium (juízo). O enunciado se apresenta, pois, como juízo. Ora, elementos do juízo são os conceitos. Por sua vez, os juízos se compõem em conclusões. Por isso, a lógica não é apenas a doutrina do juízo, mas também a doutrina do conceito, de que o juízo se compõe, e da conclusão, que se compõe de juízos (HEIDEGGER, 1998, p. 233-234).

Para Kant, o entendimento (Verstand), com os conceitos, não somente representa, como também julga a realidade (KANT, 1968, p. 84-99). A representação serve para o entendimento julgar. Julgar é a função da unidade de uma ação que ordena diversas apresentações numa representação comum. Os juízos são funções de unidade, isto é, unificações de apresentações intuitivas (Vorstellungen). No juízo, no lugar de uma apresentação imediata, intuição, temos uma representação mais abrangente, que abarca e compreende em si várias apresentações. Julgar é, pois, recolher, ajuntar, compor. Exerce a função de conjunção, de composição, de síntese. Aristóteles já dizia que o lógos apophantikós era, ao mesmo tempo, sýnthesis e diaíresis na terminologia medieval, a oratio enunciativa ou a enunciatio é compositio e divisio: composição e divisão (de-composição, distinção) (ARISTÓTELES, 1998, p. 218220)ํ. É que o juízo, a ação própria do entendimento, reúne de tal maneira que as determinações, que são reunidas, ao serem e para serem reunidas, parmenecem também distintas (desunidas). O juízo é um modo de tornar presente o real; não um modo imediato, como a intuição, mas um modo mediato, mediante conceitos; é, assim, uma representação determinante e articuladora que faz aparecer uma coisa, no discurso, como isto ou aquilo.

Para Kant, há conceitos empíricos e conceitos puros (não empíricos). A estes Kant chama de "noções" (cf. HEIDEGGER, 1991, p. 51-58). Não são conceitos refletidos, mas sim conceitos "refletentes". O entendimento que opera o pensamento, não só representa, mas também julga. A função de julgar é uma função de unificar. O julgar segue regras. Há regras que são instituídas previamente. Noções e regras se combinam na formação do sistema de predicados ontológicos, chamados pela tradição de categorias. O conceito empírico resulta da ordenação de um conteúdo intuitivo sob uma regra do entendimento. As intuições sem conceitos são cegas, os

\footnotetext{
${ }^{1}$ Aristóteles, De Anima III (Gamma) 6, 430 a 28; 430 b 3s.
} 
conceitos sem intuições são vazios. Sob o nome de "conceito puro", por sua vez, visase uma representação reflexa, cujo conteúdo, isto é, cujo "quê", por sua natureza mesma, não pode ser haurido dos e nem comprovados junto aos fenômenos, ou seja, às manifestações (o que se apresenta a e em uma intuição sensível). Chama-se de noções aos conceitos dados a priori. Os conceitos puros são representações que pertencem de antemão à estrutura essencial da reflexão. Elas atuam em, com e pela reflexão. São conceitos reflectentes, representações co-constituintes da estrutura essencial da reflexão. O entendimento puro oculta uma multiplicidade de conceitos puros. Esta totalidade é o sistema dos predicados ontológicos, isto é, predicados que anunciam o ser do ente. São categorias: quantidade, qualidade, relação, modalidade.

Ao tratar do problema da estruturação do real em objeto e objetualidade, Kant segue uma convicção que perpassa a história do pensamento ocidental desde Platão e Aristóteles, a saber, a de que essa estrutura do real é sempre lógica em seus fundamentos de estruturação. Desde Platão e Aristóteles o lógos apophantikós se tornou o fio condutor para tratar do ente e dos seus modos de ser mais abrangentes e fundamentais. Assim, no ocidente se firmou a convicção de que os modos de ser seguem os padrões dos modos de dizer, ordenados em nexos de fundamentação. Assim, nesta tradição, a estrutura sentencial subministra o paradigma de base, dá o modelo fundamental para a estrutura essencial do real enquanto tal e como um todo. Ora, as estruturas essenciais dos modos de ser do real enquanto tal e como um todo são as categorias. Deste modo, é com base na estruturação dos juízos que Kant deduz as categorias (dedução no sentido de uma quaestio iuris e não no sentido de uma quaestio facti) (KANT, 1968, p. 99-130).

Conhecimento puro é o conhecimento onto-lógico. Há, pois, um conhecimento a priori, que é o conhecimento ontológico, o conhecimento do ser do ente, isto é, da objetualidade do objeto. O conhecimento a priori, que, por sua vez, trata da possibilidade do conhecimento a priori de objetos, é chamado de transcendental. O transcendental concerne não ao conhecimento de objetos, mas ao nosso modo de conhecer objetos, na medida em que eles podem ser conhecidos a priori.

Kant, porém, ao considerar as categorias, se contenta com o trazer-à-forma do conceito enquanto função do entendimento. O conceito de forma lhe basta. Para ele, 
o conceito de intuição fica circunscrito ao âmbito do sensível. Intuição é a apresentação (representação no sentido de apresentação) de algo que é dado num acesso direto e imediato. O intuído é trazido à forma mediante o conceito. É material para a forma conceitual. O trazer à forma é, contudo, apenas uma função do entendimento. Algo como intuição categorial não faz sentido neste modo de conceber, seja intuição (como apenas intuição sensível) seja categorias (como apenas forma).

\section{Categoria, doação e datidade do ser}

A expressão "intuição categorial” traz em sua significação o seguinte teor: que a categoria é mais do que forma. É uma intuição que deixa vir à luz uma categoria, isto é, um modo fundamental de ser que diz respeito ao ente cada vez em questão ou ao ente no todo. Há um tornar presente que, imediatamente, se dirige a uma categoria, ou seja, a uma determinação fundamental do ente. Em suma, "intuição categorial" diz que o categorial é dado, doado, vale dizer, constitui uma datidade (Gegebenheit) (HEIDEGGER, 1986, p. 375).

Voltemos ao exemplo do livro de capa amarela. Nós o tomamos, aqui, como exemplo de objeto sensível. Eu o percebo - a este objeto — como uma coisa. Colhoo como uma substância. Mas, onde está a substância, neste livro? Eu não percebo a substância, em todo o caso, do mesmo modo como percebo este livro. E, no entanto, eu vejo, quer dizer, percebo, capto, apreendo, a substância (o ser em si). Se, vivendo em minha percepção, eu não percebesse (com a mente, intelectivamente), a determinação de ser dando-se enquanto substância (ser em si), eu nem mesmo poderia apreender o livro enquanto livro, isto é, enquanto uma coisa-de-uso feita para a leitura, compreendida em sua manualidade-instrumentalidade; enquanto coisa contraposta a mim (Gegen-stand), compreendida em sua oposição, resistência e irredutibilidade, que me vem ao encontro no interior de uma paisagem (Gegend) do real; enfim, enquanto objeto, ou seja, enquanto algo que se me apresenta e que eu tenho presente em referência a mim (Objekt), o qual pode se tornar tema (Thema) de meu conhecer e dizer, sobre o qual eu posso falar e que, assim, numa proposição, pode vir a se tornar sujeito (Subjekt) de meu enunciado, como quando, por exemplo, eu digo: "este livro é amarelo". Uma determinação de ser — uma predicado ontológico — não é visível, 
apreensível, como é um predicado ôntico, isto é, do ente, da coisa (res) em questão (predicado real). O ser-substância do livro não é captável no mesmo modo como o seu ser-amarelo. Se tomarmos o sensível como visível (captável) e o não sensível, o categorial, o ontológico, como invisível, então podemos dizer: para ver o visível (sensível) é preciso ver (captar) o invisível (o não-sensível). Vemos o visível no invisível. O nosso perceber nunca é um mero receber impressões, sensações, dados hiléticos. É mais do que isso. O nosso perceber é já sempre ambas as coisas: visão (captação) do visível (sensível) e do invisível (não-sensível). Nosso perceber é já sempre, isto é, por princípio, captação sensível e categorial, ôntica e ontológica.

O nosso perceber se exercita já sempre em um e como um compreender do ser do ente. Por isso, em todo enunciado há sempre um excedente, um plus, em relação ao sensível. Se eu digo: “este livro é amarelo e pequeno”, há significações que se preenchem com dados sensíveis, como "livro", "amarelo”, “pequeno", mas há também significações que se preenchem com dados não sensíveis (“este”, "é”, "e”). O estado de coisas anunciado se dá no enunciado, constituindo-se por um ato de síntese (composição, reunião, unificação). Esta síntese compõe o sensível e o categorial. Mesmo quando dizemos, simplesmente: "o livro é” — no "é" se expressa já um excedente. A significação do "é” é intuída no modo de uma intuição categorial. O ser (aqui, no sentido de presença ou de existência), dado com este "é", excede os dados das afecções sensíveis. O ser é visto, captado, numa simples apreensão. O ser é apreendido de modo diverso de como o ente o é. No presente, captamos a presença. No existente, a existência. Na coisa, a coisalidade (o caráter-de-ser-coisal). Na coisade-uso, no instrumento, a instrumentalidade. No objeto, a objetualidade. Nossa captação, deste modo, em sendo compreensão, é sempre bifurcada. E é sempre composta de sensível e categorial, de ôntico e ontológico.

Entretanto, para que o categorial-ontológico, o caráter ou o modo de ser, seja captado é preciso que ele seja dado. Intuição categorial diz que esta doação e sua datidade acontece. E diz isto seguindo pela via da analogia: diz que o categorialontológico é dado, assim como o sensível-ôntico, embora diversamente. Há uma semelhança no caráter-de-ser-doado (datidade). Há uma diferença no modo como acontece a doação e, respectivamente, a captação. A doação de ser acontece, mas não 
acontece do mesmo modo que acontece a doação do ente. A captação do ser acontece, mas não acontece do mesmo modo que acontece a captação do ente. Temos, numa dimensão, o sensível dando-se em correlação ao modo de captação do sentir. Temos, noutra dimensão, o inteligível dando-se em correlação ao modo de captação do inteligir. Tudo o que percebemos captamos, por assim dizer, como uma construção em dois andares.

Pelo caminho da analogia, se instaura uma correspondência. Nesta analogia, o sensível-ôntico é o analogado principal, a base, o andar de baixo. O categorialontológico é o analogado secundário, a sobre-estrutura, o andar de cima. Esta ordenação, porém, não diz tanto respeito às coisas enquanto tais, mas ao nosso modo de captação das coisas. Primário é o que é mais acessível a nós, o que nos é mais próximo, numa tematização. Secundário é o que é menos acessível, o mais distante, numa tematização. $\mathrm{O}$ homem, em sendo homem, exercer o seu viver tanto na imanência do comércio (intercâmbio) com os entes, quanto na transcendência da compreensão do ser. Mas o que é primeiro na ordem do ser — é o último na ordem do nosso conhecer temático, reflexivo, explícito. E vice-versa: o que é primeiro na ordem do nosso conhecer temático, reflexivo, explícito, é o último na ordem do ser. Ainda que seja com estas restrições, impostas pela via da analogia, a descoberta fenomenológica da intuição categorial dá acesso a um achado fundamental: a datidade categorial, ontológica, ou seja, à doação das determinações do ser, à doação do ser mesmo e sua datidade. É uma datidade a priori. Dizendo positivamente: a compreensão do ser é o que antecede - com uma antecedência constitutiva e não meramente temporal — todo o nosso relacionamento com o ente.

Outra contribuição decisiva da intuição categorial consiste em que, com ela, o ser se liberta do juízo. Como assim? Tomemos um exemplo. Quando vejo o papel branco e expresso isso que vejo dizendo: "este papel é branco" - eu dou expressão não só ao que é apreendido de modo sensível: o papel, o branco. Dou expressão, fundamentalmente, ao ser-branco do papel. O ser-branco do papel é diverso do branco. Com o meu enunciado, estou dando expressão ao ser-branco do papel. Capto e dou expressão não simplesmente ao papel e ao branco, mas ao estado de coisas: papel sendo branco. Capto não somente o papel presente, mas a presença, vale dizer, a existência deste papel aqui, que está posto diante de mim. Capto o papel como sendo 
e sendo em si (ens in se: substantia). Capto o ser-branco como um momento deste papel, que está sendo. Compreendo que este momento não é necessário para que um papel seja papel. Compreendo que o ser-branco do papel é um dado casual, que o papel poderia ser amarelo, por exemplo. Compreendemos que um papel por e para ser papel não precisa ser branco. O ser-branco é uma determinação do papel, uma cor, uma qualidade, um ser-assim de alguma coisa, e, enquanto tal, algo em outro (in alio: accidens, acidente).

Em todo o caso, a captação de ser é diversa da captação do que está sendo. Porque o ser não se manifesta como ente, porque não se dá e não é captado a modo do ente, tomamo-lo como uma nulidade, ou como uma mera ficção de nosso pensamento, ou ainda como uma construção mental, ou ainda como uma mera abstração. No melhor dos casos, tomamos como categoria no sentido de forma. Em virtude de nosso esquecimento do ontológico e de sua datidade, em razão do fato de que este está sempre se abrindo e se manifestando a nós, sem que nós nos apercebamos desta abertura e manifestação, nós o tomamos por uma nulidade. Pensamos que há ser porque dizemos "x é". E não consideramos o contrário: que podemos dizer “é” porque há ser. Em vez de "há ser”, podemos dizer: “dá-se ser". E ser está sempre se dando tanto na dinâmica da percepção quanto nos vãos e abrigos da linguagem, que traz à fala o que nós percebemos. Por ser simples e imediata, porém, a doação do ser e sua datidade não é por nós tematizada, nem considerada. A revelação do ser permanece esquecida, latente, velada na linguagem.

\section{Suspeitas, acenos e desafios}

Terminemos esta reflexão com algumas considerações finais, que expomos em forma de suspeitas e de acenos.

Se consideramos que só na doação do ser é que pode acontecer a doação do ente — pois, como pode o ente ser sem o ser? —; se tomarmos em consideração que só na manifestação - abertura — do ente é que pode acontecer a manifestação — o descobrimento - do ente; então não deveríamos dar um passo além da analogia e dizer que o ser é o fenômeno originário? Não seria a parousía do ser — seu advento, sua chegada, sua irrupção - e sua epiphanía, seu brilho, sua manifestação, o 
arquifenômeno, a coisa mesma do pensar? Não é assim a fenomenologia do fenômeno em sentido mais próprio e fundamental, o que deixa ser no seu próprio, na sua diferença, o fenômeno (o vir à luz e brilhar) de tudo o que está sendo?

Se for assim, a descoberta da intuição categorial não nos levaria para além e para fora do contexto em que ela se deu, a saber, no contexto da cisão e distinção de sensível e inteligível e da distinção de sensibilidade e razão, e para além e para fora da via em que ela foi acessada e estabelecida, a via da analogia? Parece que sim. Que outro contexto albergaria este achado? Em que outra dimensão de pensamento se abriria o espaço para o lógos deste arquifenômeno do advento e da doação do ser? Não seria em uma dimensão anterior a toda a cisão, na dimensão de todas as dimensões, a da unidade simples do ser ela mesma? Não é para aí que se encaminha um pensamento essencial, um pensamento do ser? Este encaminhamento se dá, na história do pensamento contemporâneo, na passagem da fenomenologia de Husserl para a fenomenologia de Heidegger?

Re-fazer esta passagem e continuar passando, num abrir caminho incessante, é, a nosso ver, um grande desafio do presente da fenomenologia e da fenomenologia do presente. Neste contínuo passar todo o pensado e dito se apresenta em caráter de provisoriedade. Esta reflexão quis ser uma contribuição provisória no encaminhamento da fenomenologia de nosso presente. Em jogo está o encaminhamento para a e na “Clareira do Ser". Muitos são os cerrados em torno dessa clareira. Há veredas solicitando ser percorridas. Oxalá consigamos abrir as nossas próprias picadas e descobrir as nossas próprias veredas no imenso cerrado do ser.

\section{Referências}

ARISTOTELES. Anima (testo greco a fronte). Milano: Rusconi, 1998.

HEIDEGGER, M. Seminare (GA 15). Frankfurt am Main: Vittorio Klostermann, 1986.

HEIDEGGER, M. Kant und das Problem der Metaphysik. Frankfurt am Main: Vittorio Klostermann, 1991.

HEIDEGGER, M. Die Grundprobleme der Phänomenologie (GA 24). Frankfurt am Main: Vittorio Klostermann, 1997. 
HEIDEGGER, M. Heráclito: a origem do pensamento ocidental. Lógica: a doutrina heraclítica do lógos. Rio de Janeiro: Relume Dumará, 1998.

HEIDEGGER, M. Conferências e escritos filosóficos. São Paulo: Nova Cultural, 1999.

HUSSERL, E. Logische Untersuchungen: Elemente einer phänomenologischen Aufklärung der Erkenntnis. Tübingen: Max Niemeyer, 1993.

KANT, I. Kritike der reinen Vernunf (Kants Werke III). Berlin: Walter de Gruyter \& Co., 1968.

LEÃO, E. C. Aprendendo a pensar I: o pensamento na modernidade e na religião. Teresópolis: Daimon, 2008.

ROMBACH, H. Die Gegenwart der Philosophie. Die Grundprobleme der abendländischen Philosophie und der gegenwärtige Stand des philosophischen Fragens. Freiburg / München: Karl Alber, 1988. 